\title{
RESEARCH OF PROCESSES OF HYDROGEN EXTRACTION FROM THE GAS MIXTURE FORMED DURING THE HYDROGEN SULFIDE DECOMPOSITION
}

\section{Arkadii Proskurin ${ }^{1}$ \\ Yurii Halynkin²}

DOI: https://doi.org/10.30525/978-9934-588-15-0-60

\begin{abstract}
The theoretical and experimental principles and design solutions for the technology for the extraction of hydrogen from gas mixtures formed during the decomposition of hydrogen sulfide using metal hydride technologies, allowing to obtain hydrogen of high purity and pressure, are considered. Analytical equations and dependences of the physicochemical properties of reversible metal hydrides and basic organic liquids that can be used as carriers are determined. It was determined that the enthalpy $(\Delta H)$ and entropy $(\Delta S)$ formation of metal hydrides are the most important parameters and their value determines the processes of absorption and desorption, as well as hysteresis. An experimental device has been created to study the processes of hydrogen extraction from the decomposition products of hydrogen sulfide and its compression at high pressures. A schematic diagram of a thermal sorption compressor device has been developed, which is suitable for use in industrial devices for compressing hydrogen obtained from the black sea hydrogen sulfide. The dependences of the mass fraction of hydrogen absorption in the separator sorber on the suspension temperature and its residence time in contact with the gas mixture at a pressure of 0.3 and $0.6 \mathrm{MPa}$ are determined. The productivity of the process of extracting hydrogen from a gas mixture has been established. The dependences of the device productivity on the pressure of the mixture in the sorber and the pressure of hydrogen in the stripper and the temperature of the suspension are
\end{abstract}

\footnotetext{
${ }^{1}$ Candidate of Engineering Sciences, Assistant Professor at Department of Internal Combustion Engines, Plants and Operation,

Admiral Makarov National University of Shipbuilding, Ukraine

${ }^{2}$ Candidate of Engineering Sciences, Lecturer at Department of

Mechanical Engineering and Manufacturing Engineering,

Admiral Makarov National University of Shipbuilding, Ukraine
} 
established. The characteristics of hydrogen absorption at a suspension temperature of $298 \ldots 313 \mathrm{~K}$ and in the pressure range $0.2 \ldots 0.3 \mathrm{MPa}$ are presented. The dynamics of the relative mass of hydrogen of the battery/ compressor freed from high pressure was studied, depending on the heating temperature. The effectiveness of the metal hydride thermal sorption device for the extraction of hydrogen from the decomposition products of hydrogen sulfide is evaluated. It is determined that the energy efficiency of the experimental device in-creases with increasing pressure of the gas mixture in the sorption device. Indeed, the energy efficiency of the experimental device for extracting hydrogen from a gas mixture and compressing this hydrogen to high pressures is calculated.

\section{Introduction}

The Black Sea is the largest meromictic water basin on our planet, a characteristic feature of which is the presence of a relatively thin layer of aerobic waters and a powerful hydrogen sulfide zone $\left(\mathrm{H}_{2} \mathrm{~S}\right.$ zone), which is located at depths of more than $90 \ldots 160 \mathrm{~m}$ and occupies about $87 \%$ of the sea volume [1, p. 57]. Hydrogen sulfide is a high-calorie compound and can be used as an independent energy fuel. However, to date, hydrogen sulfide from the deep sea has not found such an application. In turn, the huge $\mathrm{H}_{2} \mathrm{~S}$ deposits in the Black Sea are a global source for producing hydrogen and sulfur. According to reports, the total amount of hydrogen sulfide is estimated at $40 \ldots 50$ billion tons. Only its annual growth is estimated at $0.01 \ldots 0.1$ million tons [2, p. 32]. The hydrogen sulfide content in the bottom layer of water varies from 0.3 to $10 \ldots 12 \mathrm{mg} / \mathrm{l}$. In sediments of the bottom, it ranges from 25 to $240 \mathrm{mg} / \mathrm{l}$ [2]. However, despite the presence of huge reserves in the Black Sea, the extraction of $\mathrm{H}_{2} \mathrm{~S}$ is associated with huge energy difficulties. These difficulties are primarily caused by the following factors [3, p. 26]: in sea water, $\mathrm{H}_{2} \mathrm{~S}$ is present not only in a free, but also in a bound state, as a part of hydrosulfites; the need to lift saturated deep hydrogen sulfide masses of sea water; the need to separate hydrogen sulfide from seawater; the need to extract hydrogen from the gas mixture formed during the decomposition of hydrogen sulfide.

One of the effective methods for solving the problem of extracting hydrogen from a gas mixture is the use of metal hydride technologies, allowing to obtain hydrogen of high purity and pressure. Metal hydrides 
are capable of reacting with hydrogen and creating chemical compounds with a high content of atomic hydrogen. Some of these hydride-releasing compounds are reversible: they are able to absorb hydrogen during heat extraction and to release it when heat is supplied. These compounds are solid fine powders. An important fundamental property of these materials is the absorption of atomic hydrogen and insensitivity to the absorption of other gases. This property allows to create a device for the effective extraction of hydrogen from gas mixtures.

The unique properties of metal hydrides can be used in thermochemical cycles and devices for compressing hydrogen to high pressures [4, p. 38]. There are many devices that work using these properties, but they all have one significant drawback - the discrete (cyclic) principle of operation. This determines the low thermodynamic efficiency, extremely complex control system and the high cost of these devices, respectively.

Compression processes based on metal hydride technology and, accordingly, technical devices, can be effective only when a continuous process is implemented in these devices. Continuous operation of a thermal absorption compressor device can be realized using metal hydrides in the form of a suspension in an organic liquid. This allows to transport metal hydrides between the elements of the device, thereby increasing thermodynamic efficiency, significantly reducing the weight and dimensions and cost of the system.

\section{Basic equations and dependences of physico-chemical properties of reversible metal hydrides and basic organic liquids}

The most important is the parametric dependence of the properties of metal hydrides: pressure - temperature - concentration. In this sense, the possibility of using the Van Hoff relations for the temperature dependence of the logarithm of the pressure of hydrogen sorption/desorption was investigated. The Van Hoff equation in accordance with the relations of chemical thermodynamics, with changes in temperature $(T)$, equilibrium constant $(K)$ is given in the change in the standard enthalpy $(\Delta H)$ for this process, has the following form $[5$, p. 21]:

$$
\frac{d \ln K}{d T}=\frac{\Delta H}{R T^{2}}
$$


If to take the reaction enthalpy at a variable temperature unchanged, then a certain interval of this differential equation for temperatures $T_{1}$ and $T_{2}$ has the form:

$$
\ln \left(\frac{K_{2}}{K_{1}}\right)=\frac{-\Delta H}{R}\left(\frac{1}{T_{2}}-\frac{1}{T_{1}}\right)
$$

In this equation, $K_{1}$ is the equilibrium constant at absolute temperature $T_{1}$ and $K_{2}$ is the equilibrium constant at absolute temperature $T_{2} . \Delta H$ is the standard enthalpy and $R$ is the gas constant.

In this way

and

$$
\Delta G=\Delta H-T \Delta S
$$

$$
\Delta G=-R T \ln K .
$$

therefore

$$
\ln K=-\frac{\Delta H}{R T}+\frac{\Delta S}{R} .
$$

Thus, the graph of the natural logarithm of the equilibrium constant is displayed by a straight line. The slope of the line is equal to the ratio of the standard enthalpy in the gas constant $\Delta H / R$ and the absolute temperature $\mathrm{T}$ with a minus sign and the ratio of the standard entropy in the gas constant $\Delta S / R$ with a plus sign.

The differentiation of this equation leads to the Van Hoff equation [6, p. 62].

The Arrhenius equation determines the dependence of the equilibrium constant of a chemical reaction $k$ on temperature $T$ and activation energy $E_{a}$, as shown below:

$$
k=A e^{-E a / R T} .
$$

Here $A$ is the coefficient of proportionality before the exponential function or, more simply, the pre-factor and $R$ is the gas constant. The proportionality coefficient values are identical at a constant reaction rate and vary depending on the type of reaction. If a first-order reaction takes place, then the proportionality coefficient has a dimension of $\mathrm{s}^{-1}$, in connection with this it is often called the frequency factor or the frequency of the reaction attempt. More simply, $k$ is the number of collisions per second that leads to a reaction, $A$ is the total number of collisions (which leads to a reaction or not) per second, and $e^{-E a / R T}$ is the probability that any collision will lead 
to a reaction. When the activation energy is provided in molecular devices instead of mole devices, for example, Joule per molecule instead of Joule per mole, the Boltzmann constant is used instead of the gas constant. It should be noted that an increase in temperature or a decrease in activation energy leads to an increase in the reaction rate.

Molecular hydrogen under ordinary conditions - at pressures up to $100 \mathrm{MPa}$ and temperatures $298 \ldots 323 \mathrm{~K}$ - interacts only with a limited number of metals, but exclusively with metals that have a low ionization potential: alkali and rare-earth metals, etc.

The hydride formation enthalpy is an important parameter that characterizes a compound that can be used as sorbent for various applications. If the range of $\Delta H$ values is in the range of $25 \ldots 50 \mathrm{~kJ} \times \mathrm{mol}^{-1}$, then such a compound is suitable for use in devices for the compression and extraction of hydrogen.

The heat of formation of a stable reversible hydride compound is within $15 \ldots 40 \mathrm{~kJ} \times \mathrm{ml}^{-1}$. When this heat is below $15 \mathrm{~kJ} \times \mathrm{ml}^{-1}$, the hydride compound is not stable enough to charge the metal hydrides at three ambient temperatures. On the other hand, the hydride compound is very resistant to desorption at ambient temperature when $\Delta H$ exceeds $50 \mathrm{~kJ} \times \mathrm{ml}^{-1}$.

In general, the difference in standard entropy $(\Delta S)$ between the hydride-forming composition and the hydride (hysteresis) is small and amounts to about $10 \mathrm{~kJ} \times \mathrm{ml}^{-1} \times \mathrm{K}^{-1}$.

Changes in the entropy of hydride formation are primarily ensured by the loss of standard hydrogen entropy $\left(130.858 \mathrm{~J} \times \mathrm{ml}^{-1} \times \mathrm{K}^{-1}\right.$ at $\left.298 \mathrm{~K}\right)$, which means that $\Delta S$ can be accepted as a constant and independent of the nature of hydride-forming compounds.

Efficient hydrogen embedding and its compression to high pressures can be achieved by using metal hydride compounds of the type $L a N i_{5-x}$ $A l_{\mathrm{x}}$ або $M m \mathrm{Ni}_{5-\mathrm{x}} A l_{\mathrm{x}}$. The choice of such materials is due, firstly, to the fact that these materials provide a sufficiently high speed of the hydrogen sorption process at low pressures $(0.15 \ldots 0.25 \mathrm{MPa})$ and moderate temperatures $(288 \ldots 318 \mathrm{~K})$ of the process, and make it possible to obtain relatively high hydrogen pressures at moderate temperatures (353...373 K). Such characteristics of hydride-releasing compounds make it possible to avoid, on the one hand, significant dissolution of associated gases $\left(\mathrm{CO}, \mathrm{CO}_{2}, \mathrm{H}_{2} \mathrm{~S}, \mathrm{CH}_{4}\right.$, $\mathrm{C}_{m} \mathrm{H}_{n}$ ) in a liquid organic carrier during the sorption of hydrogen from the 
mixture, and, on the other hand, prevent the release of these gases from the organic carrier during hydrogen desorption from metal hydrides. Secondly, metal hydride compounds of the type $L a N i_{5-\mathrm{x}} A l_{\mathrm{x}}$ or $\mathrm{Mm} \mathrm{Ni} \mathrm{i}_{5-\mathrm{x}} A l_{\mathrm{x}}$ are sufficiently resistant to poisoning by the constituents of the gas mixture and other chemicals that may be present in the suspension.

Figure 1 presents linearization of the temperature dependence of hydrogen pressure for various hydride-releasing compounds is given. This diagram shows the results without taking into account hysteresis, since in the range of operating parameters of the experimental bench and in the future field device, this phenomenon can be neglected without a significant error in the results.

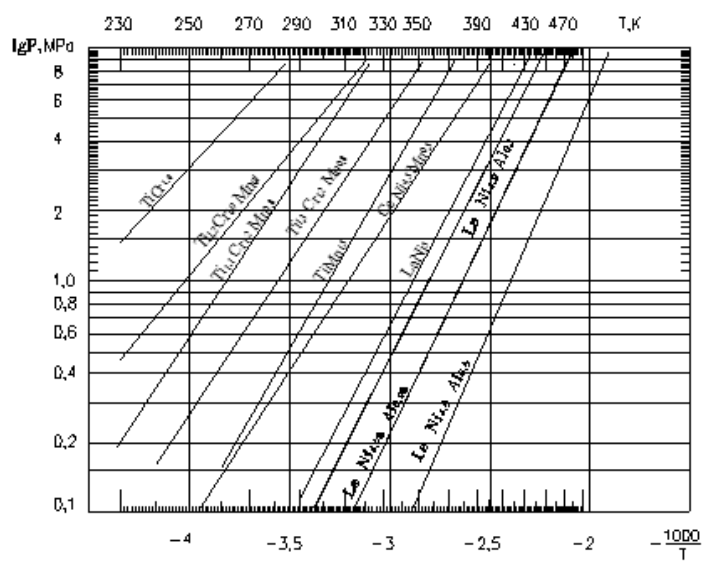

\section{Figure 1. Linearization of the temperature dependence of hydrogen pressure for various hydride-releasing compounds (excluding hysteresis)}

An analysis of the data presented in Figure 1 shows that the most effective should be considered hydride-releasing compounds, the properties of which lie within the compounds of the lantate, nickel and aluminum $\mathrm{LaNi}_{5}-\mathrm{LaNi}_{4,5} \mathrm{Al}_{0,5}$.

The results of experimental studies indicate that the most appropriate is the use of intermetallic compound $\mathrm{Mm} \mathrm{Ni}_{4.5} \mathrm{Al}_{0,5}$. as a hydride-soluble compound.

It is advisable to use the compound $\mathrm{MC}-40$ as a mischmetal (Mm), which contains $60 \%$ cerium and $40 \%$ lanthanum, which allows not only to reduce the cost of the material, but also to increase its resistance to poisoning. 


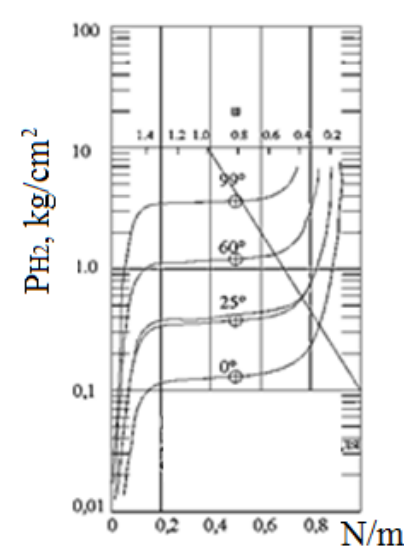

Figure 2. Isotherms of hydrogen absorption and desorption for the $M m N i_{4,5} A l_{0,5}$ compound

Figure 2 shows the experimentally obtained hydrogen absorption and desorption isotherms for the hydride-releasing compound $M m N i_{4,5} A l_{0,5}$. These data indicate that the absorption of hydrogen from the gas mixture can be effectively carried out at temperatures of 298...318 K, and the partial pressure of hydrogen in this case should be within $0.1 \mathrm{MPa}$. To ensure high rates of the sorption process, it is advisable to have a partial pressure of hydrogen at the level of $0.15 \ldots 0.25 \mathrm{MPa}$, which, on the one hand, will accelerate the speed of the process, and on the other, it will limit the solubility of associated gases $\left(\mathrm{CO}, \mathrm{CO}_{2}, \mathrm{H}_{2} \mathrm{~S}, \mathrm{CH}_{4}\right.$, $\mathrm{C}_{\mathrm{m}} H_{\mathrm{n}}$ ), which are present in the mixture upon decomposition of hydrogen sulfide.

To reduce or eliminate the evolution of these gases, which are nevertheless dissolved in a liquid organic carrier, for the desorption of purified hydrogen, it is necessary to maintain the process temperature at the level of $363 \ldots 383 \mathrm{~K}$ and ensure the extraction of high-purity hydrogen.

Further compression of hydrogen to pressures of $15 . .20 \mathrm{MPa}$ can be achieved in discrete action using the same compound. However, taking into account the fact that the hydrogen that is supplied to the compression is free of associated gases, the process temperature can be raised to $523 \ldots 573 \mathrm{~K}$. This will provide a predetermined compression pressure within $15 . .20 \mathrm{MPa}$. The discrete principle of operation of a thermochemical hydride compressor allows the final purification of hydrogen from impurities of associated gases. The process is as follows. After the end of the sorption process in a thermochemical metal hydride compressor using a hot coolant (organic high-temperature liquid such as ПМС-200), the hydrogen pressure in this apparatus rises to 1.0..1.5 MPa. Next, the valve opens for the release of contaminated hydrogen into the candle, where it is burned. The release time of contaminated hydrogen is $3 \ldots .5 \mathrm{~s}$. After that, the temperature of the hot coolant rises to $523 \ldots 573 \mathrm{~K}$, providing the necessary hydrogen pressure in the range of $15 \ldots 20 \mathrm{MPa}$. In this case, it is possible to achieve a hydrogen 
purity of 99.9999 , but in practice, taking into account the contamination of pipelines, fittings, etc., it is realistic to obtain hydrogen with a purity of 99.99 .

\section{Experimental device for hydrogen extraction from products of hydrogen sulfide decomposition and its compression at high pressures}

A schematic diagram of an experimental device for the hydrogen extraction from the decomposition products of hydrogen sulfide and its compression at high pressures is shown in Figure 3. Device works as follows. The gas mixture with a high volumetric hydrogen content (up to 72\%) is supplied through the reducer 7 to the adsorber 6 where it is absorbed by the hydride-releasing composition $\mathrm{MmNi}_{4,5} \mathrm{Al}_{0,5}$. In this case, the heat of the hydride formation reaction is removed by cold coolant, which is supplied by pump 5 . Since not all hydrogen is absorbed by the hydride-releasing composition, part of it is supplied to recirculation, and the rest of the gas mixture with low hydrogen content is removed and can be used in a heat engine to generate electricity with the purpose of providing energy to the device.

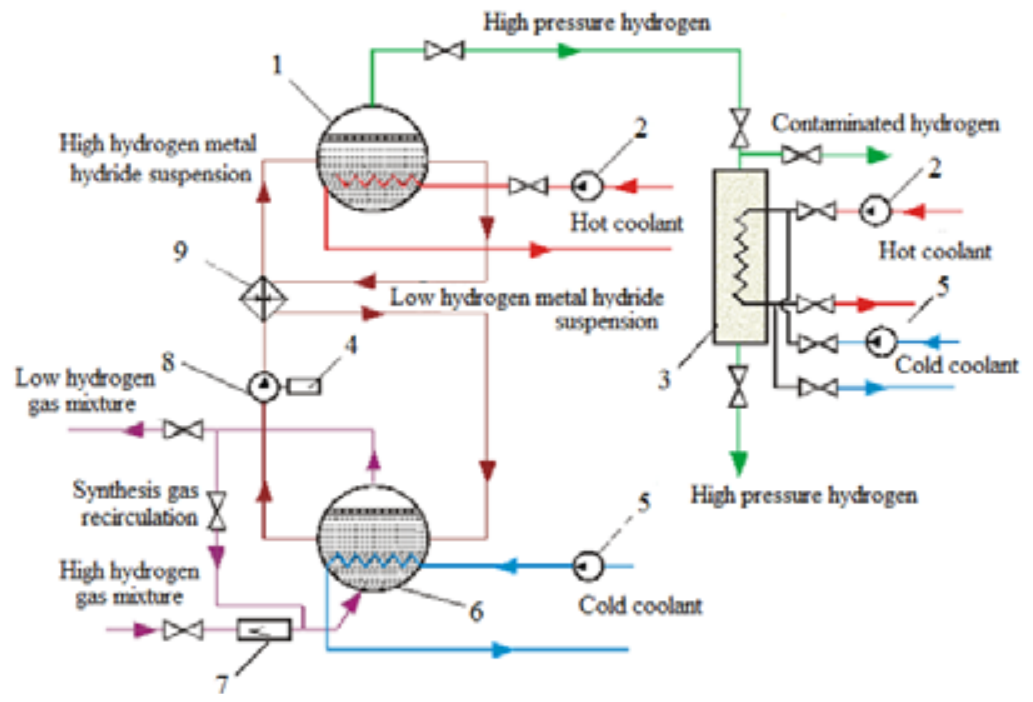

Figure 3. Scheme of an experimental device

for the extraction of hydrogen from the decomposition products of hydrogen sulfide and its compression at high pressures 
Next, the suspension of metal hydrides $\mathrm{MmNi}_{4,5} \mathrm{Al}_{0,5} \mathrm{H}_{6}$ is supplied through the membrane pump 8 through the heat exchanger-heater of the suspension 9 to the stripper 1. In order to desorb the purified hydrogen from the hydride, hot coolant with a temperature of $363 \ldots 383 \mathrm{~K}$ is supplied to this apparatus using pump 2 that provides a hydrogen pressure of $0.8 \ldots 1.2 \mathrm{MPa}$. From stripper 1, purified hydrogen with the specified pressure enters the battery-compressor 3, where MmNi4.5Al0.5 intermetallic compounds are absorbed. The heat of reaction is removed by means of a coolant using pump 5. After filling this apparatus with hydrogen, the valve is shut off, a hot fluid with a temperature of $323 \ldots 353 \mathrm{~K}$ is supplied, providing a hydrogen pressure of $0.15 \ldots 0.25 \mathrm{MPa}$. In this case, the corresponding valve opens and hydrogen is removed from the compressor battery with residual contaminants that could get into the hydrogen during degassing of the liquid organic carrier stripper 1 . After purging, the valve closes and the temperature of the hot coolant rises to $523 \ldots 573 \mathrm{~K}$, providing hydrogen pressure of ha level $15 . .20 \mathrm{MPa}$.

Figure 4 shows the final agreement on the concept of a thermal sorption compressor device, which is suitable for use in industrial devices for compressing hydrogen obtained from the Black Sea hydrogen sulfide to high pressures.

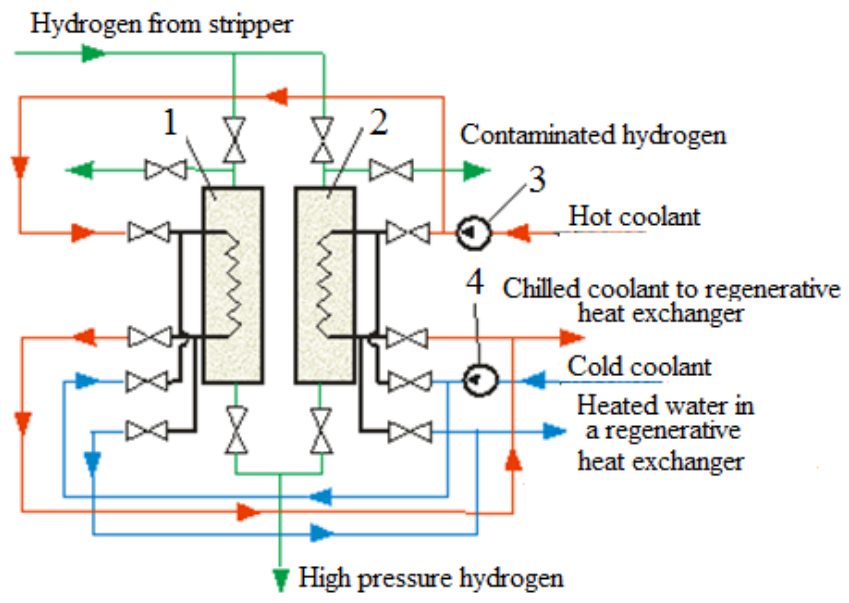

Figure 4. Schematic diagram of a cyclic thermal sorption compressor for an industrial device: 1,4 - thermal sorption battery-compressor; 2 - hot coolant pump; 3 - cold coolant pump 
This circuit diagram is practically different in that it consists of two metal hydride compressor devices that operate cyclically and provide a continuous supply of high pressure hydrogen to the consumer.

Also, the technical solution is characterized in that the cold heat carrier, which is used to cool the apparatus of the compressor device, is not discharged into the environment, but used as an additional energy source for heating the hot heat carrier in front of the boiler. This additional measure does not significantly affect the fundamental decision, but allows to save up to $3.0 \ldots 3.5 \%$ of thermal energy. The structure of the device includes a certain number of heat exchangers designed for cooling and heating a suspension of hydride-releasing material, hydrogen and other liquids.

\section{The results of experimental studies \\ of hydrogen extraction processes from the gas mixture formed during the hydrogen sulfide decomposition}

The decomposition products of hydrogen sulfide and related substances that were obtained from the deep layers of the Black Sea were modeled using a mixture whose composition can be determined with a certain error in Table 1.

Table 1

\section{Decomposition products of hydrogen sulfide}

\begin{tabular}{|c|c|}
\hline Product & $\begin{array}{c}\text { Concentration, } \\
\text { \% (vol.) }\end{array}$ \\
\hline $\mathrm{H}_{2}$ & 71 \\
\hline $\mathrm{SO}_{2}$ & 4 \\
\hline $\mathrm{SO}_{3}$ & 3 \\
\hline $\mathrm{CO}_{2}$ & 2 \\
\hline $\mathrm{N}_{2}$ & 7 \\
\hline $\mathrm{H}_{2} \mathrm{O}$ steam & 5 \\
\hline unbalance & 8 \\
\hline Generally: & 100 \\
\hline
\end{tabular}

The experience of previous studies that were carried out to study the properties of hydride-releasing materials suggests that such an error does not have a noticeable effect on the operation of the hydrogen separator and the processes that occur in this apparatus. In addition, based on the actual operating conditions of the device for producing a gas mixture during the 
decomposition of hydrogen sulfide, it can be expected that the composition of the mixture will be significantly dependent on the parameters of the decomposition process and will fluctuate over a fairly wide range.

The suspension of hydride-releasing material consisted of $1 \mathrm{~kg}$ of $\mathrm{LaNi}_{5}$ intermetallic compound $2.5 \mathrm{~kg}$ of organosilicon liquid (PMS-5 polymethylsiloxane), the volume ratio was 1:10. This ratio was chosen on the basis of ensuring reliable formation of a suspension stable against delamination and the possibility of its transportation through the apparatuses of the experimental device without a sufficiently noticeable hydraulic resistance. The total volumetric amount of the circulating suspension was 2.75 liters, and its flow rate was $1.9 \mathrm{l} / \mathrm{min}$. The residence time of a single volume of the suspension in the sorption and desorption apparatus is approximately 50 seconds.

Figure 5 shows the kinetic characteristics of the process of hydrogen absorption from the model mixture at a pressure of $0.3 \mathrm{MPa}$ and a suspension temperature in the range $298 \ldots 313 \mathrm{~K}$. The pressure in the sorbent at the level of $0.3 \mathrm{MPa}$ ensures the minimum solubility of the accompanying gases contained in polymethylsiloxane mixtures and can stain the final product high purity hydrogen.

During a stay in the sorbent, the maximum absorption rate corresponds to a minimum suspension temperature of $298 \mathrm{~K}$. At the same time, for 50 seconds, a suspension of hydride-releasing material absorbs up to $90 \%$ of the maximum possible amount of hydrogen. Over the same period, at a temperature of $313 \mathrm{~K}$, this suspension absorbs only $60 \%$ of hydrogen from the model mixture.

Under these operating conditions, it is quite difficult to ensure the temperature of the suspension in the sorbent at the level of $298 \mathrm{~K}$, especially in the summer period, therefore, in practice, it is necessary to focus on the temperature range of $318 \ldots 323 \mathrm{~K}$, which is satisfactory enough for the process of extracting hydrogen from the gas mixture.

Such an increase in temperature will lead to a decrease in the efficiency of the device by $5 \ldots 7 \%$ compared to theoretically possible. But, if try to provide a suspension temperature of $298 \mathrm{~K}$ due to additional cooling with the help of a refrigeration machine, then the overall efficiency of the device drops by $10 \ldots 12 \%$, which gives a loss compared to the previous case of $5 \%$. Thus, the temperature range of $318 \ldots 323 \mathrm{~K}$ is quite reasonable and acceptable for real operating conditions. 


\section{Chapter «Engineering sciences»}

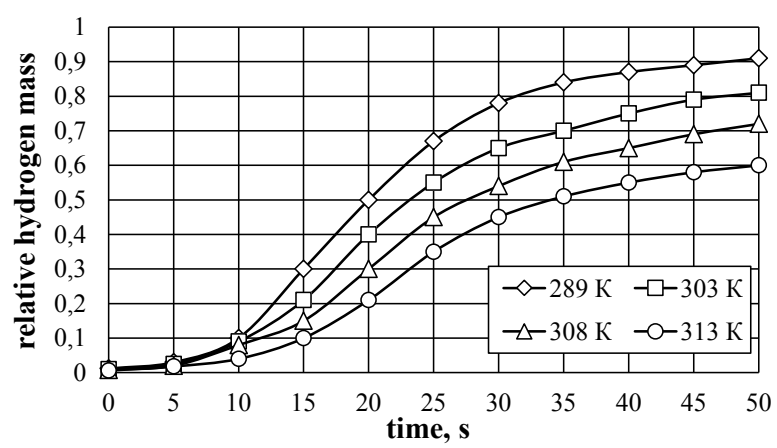

\section{Figure 5. Dependence of the mass fraction of hydrogen absorption in the separator sorber on the temperature of the suspension and the time of its stay in contact with the gas mixture at a pressure of $0.3 \mathrm{MPa}$}

Fig. 6 shows the kinetic characteristics of the process of hydrogen extraction from a suspension of hydride-releasing material at a pressure of $0.6 \mathrm{MPa}$ and a suspension temperature in the stripper at a level of $348 . .363 \mathrm{~K}$. The maximum temperature in the stripper is limited to $363 \mathrm{~K}$, taking into account the following factors. Higher desorption temperatures in this apparatus will create conditions for the release of gases from the organic liquid that were dissolved in it upon contact with the gas mixture in the sorbent and, thus, pollute hydrogen. In addition, this temperature provides fire safety when working with polymethylsiloxane. At the same time spent in the stripper for 50 seconds, the suspension of hydridereleasing material emits up to $87 \%$ of the maximum amount of hydrogen that is contained in the suspension. For the same period at a temperature of $348 \mathrm{~K}$, this suspension releases only $68 \%$ of hydrogen from a suspension of hydride-releasing material.

Along with studies of the kinetic characteristics of the experimental device, the productivity of the process of extracting hydrogen from a gas mixture was established. The dependences of the device productivity on the pressure of the mixture in the sorber and the pressure of hydrogen in the stripper and the temperature of the suspension, respectively, are established. Figure 7 shows the characteristics of hydrogen absorption at a suspension temperature of $298 \ldots 313 \mathrm{~K}$ and in the pressure range $0.2 \ldots 0.3 \mathrm{MPa}$. 


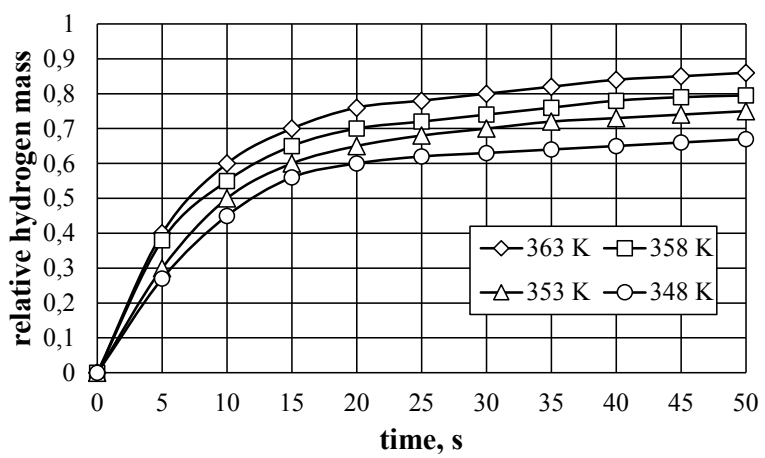

Figure 6. Dependence of the mass fraction of the withdrawn hydrogen in the stripper on the temperature of the suspension and its residence time at a pressure of $0.6 \mathrm{MPa}$

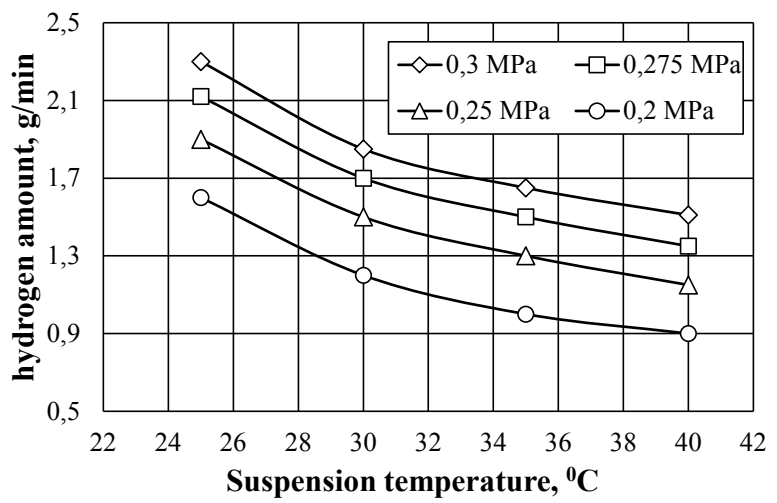

Figure 7. Characteristics of the performance of hydrogen absorption in a sorber depending on the pressure of the gas mixture and the temperature of the suspension

As experimental data show, the lowest hydrogen absorption rate at a gas mixture pressure of $0.2 \mathrm{MPa}$ and a temperature of $313 \mathrm{~K}$ is $0.9 \mathrm{~g} / \mathrm{min}$. The maximum productivity of hydrogen absorption from the gas mixture reaches $2.3 \mathrm{~g} / \mathrm{min}$ at a suspension temperature of $298 \mathrm{~K}$ in the stripper and a pressure of $0.3 \mathrm{MPa}$. 
In terms of specific indicators, such characteristics of hydrogen absorption in a sorber fully comply with the requirements for systems for the separation of hydrogen from gas mixtures. These experimental data can be used without limitation in the design of pilot industrial and industrial samples of hydrogen absorption devices not only from gas mixtures obtained by decomposition of hydrogen sulfide, but other gas mixtures containing hydrogen. The amount of hydrogen in the mixture is not significant. Metal hydride thermochemical devices of this type can effectively absorb hydrogen at its concentration in the mixture, $5 \%$ by volume.

Figure 8 shows the results of a study of the performance characteristics (the amount of hydrogen released at a pressure of $20.0 \mathrm{MPa}$ in time) of the bat-tery/compressor.

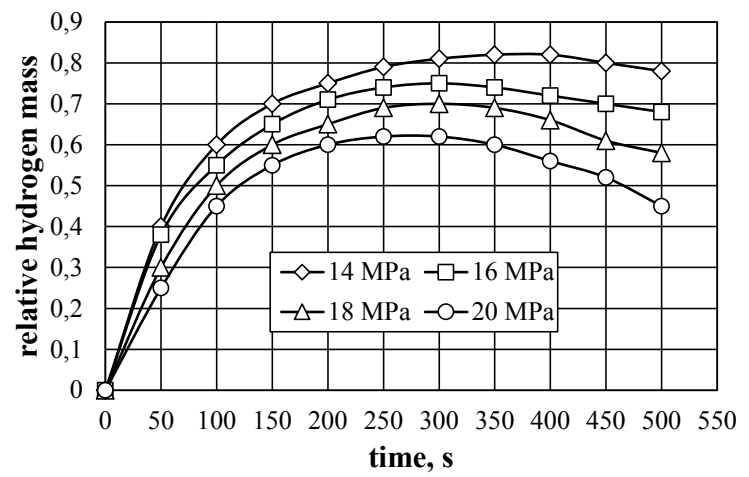

Figure 8. Relative performance characteristics of the hydride battery/ compressor depending on pressure and operating time

The research results made it possible to establish a range of performance parameters of the hydride compressor on the pressure of hydrogen and the temperature of the hot coolant, which is the energy source for this compressor. So, the maximum compressor performance is achieved at a pressure of $14.0 \mathrm{MPa}$ and a temperature of $473 \mathrm{~K}$ and is $5.8 \mathrm{~g} / \mathrm{min}$. Minimum productivity is $2.4 \mathrm{~g} / \mathrm{min}$ at a pressure of $20.0 \mathrm{MPa}$ and a temperature in the compressor of $398 \mathrm{~K}$.

Figure 9 shows the relative performance characteristics of a hydride battery/compressor depending on temperature and operating time. Relative 
performance is the ratio of the actual amount of hydrogen that is released over time from a metal hydride compressor at a given pressure and the maximum possible amount of hydrogen that can be released under ideal conditions.

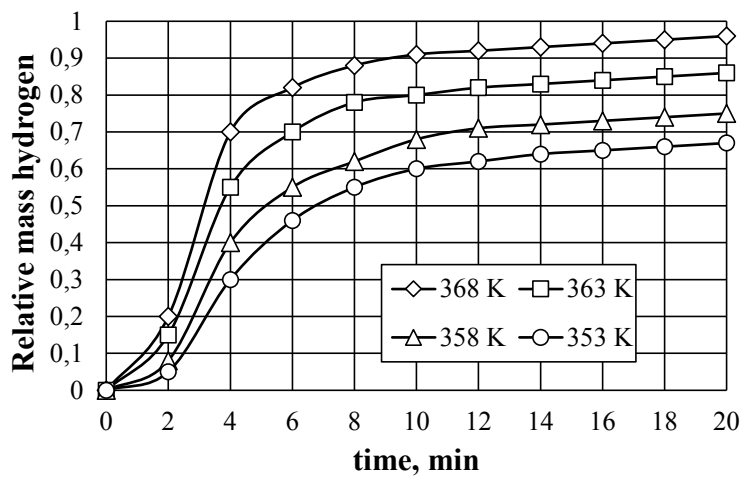

Figure 9. Experimental relative performance characteristics of the hydride bat-tery/compressor depending on pressure and operating time

From the above results it follows that the actual performance of the metal hydride compressor is in a nonlinear dependence on the pressure and temperature of the compression process.

This performance in the studied range of pressures and temperatures under the most favorable conditions reaches 0.82 and can never reach 1.0, since it has a limitation that creates hydrogen pressure.

The data presented allows to make informed decisions when designing metal hydride compressors/batteries that are designed to compress hydrogen to high pressures.

One of the important characteristics is the dynamics of the evolution of hydrogen mass and its absorption in metal hydride batteries/compressors, depending on the heating and cooling temperatures. Dynamic characteristics determine the overall performance of the device and the thermodynamic efficiency of the entire system.

The dynamics of the relative mass of hydrogen released from the high pressure of the battery / compressor depending on the heating temperature is shown in Fig. 10. These data show that an increase in the heating temperature from $75{ }^{\circ} \mathrm{C}$ to $90^{\circ} \mathrm{C}$ makes it possible to isolate at high pressure $95 \%$ 
hydrogen instead of $66.5 \%$ of the total volume that is stored in the device. The kinetics of this process increases, and the hydrogen yield increases from $0.041 \mathrm{l} / \mathrm{min}$ to $0.19 \mathrm{l} / \mathrm{min}$, and the total hydrogen yield increases from $0.600 \mathrm{l}$ to 0.9051 under the same conditions. At the 20th minute, the total hydrogen output increased from 0.6651 to 0.9501 under the same conditions.

The dynamics of the process of hydrogen absorption by sorbers is shown in Figure 10 and is characterized by the following data. A suspension of hydride-releasing material absorbs hydrogen very quickly if the temperature of the cooling water is minimal.

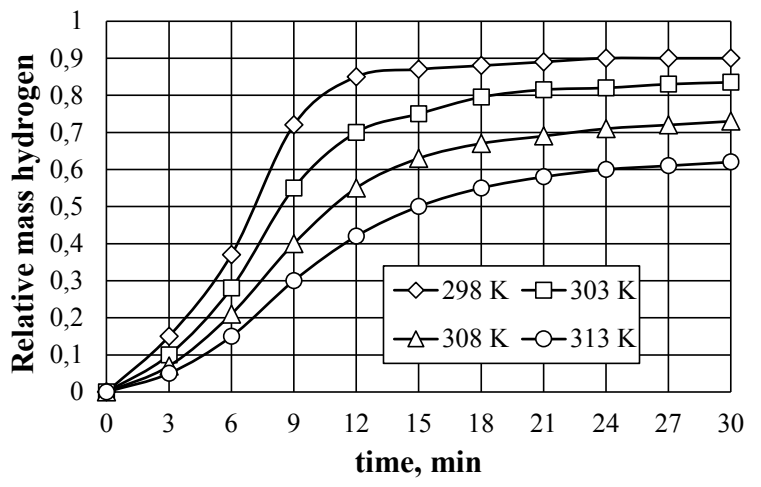

Figure 10. Relative dependence of the mass fraction of absorbed hydrogen from temperature and time

The total amount of hydrogen absorbed increased from 0.0391 to 0.151 during the first 3 minutes, while the cooling water temperature decreased from $313 \mathrm{~K}$ to $298 \mathrm{~K}$. At the 15 th minute, the total hydrogen absorption increased from 0.5051 to 0.8801 under the same conditions. At the 30th minute, the total hydrogen uptake increased from 0.6151 to 0.7251 under the same conditions.

\section{Evaluation of the effectiveness of metal hydride thermal sorption device for the hydrogen extraction from the decomposition products of hydrogen sulfide}

The experimental device for the hydrogen extraction from synthetic gas and its further compression to high pressures is based on the use of a metal hydride thermochemical continuous cycle. A suspension of hydride-releas- 
ing compound $\mathrm{MmNi}_{4.5} \mathrm{Al}_{0.5}$ in PMS-5 silicon e fluid was used as the working substance of the experimental device.

One of the most important factors that significantly affect the efficiency of the experimental device is the content of hydride-releasing material in the silicone fluid. The influence of this factor on the efficiency of the experimental device is shown in Figure 11.

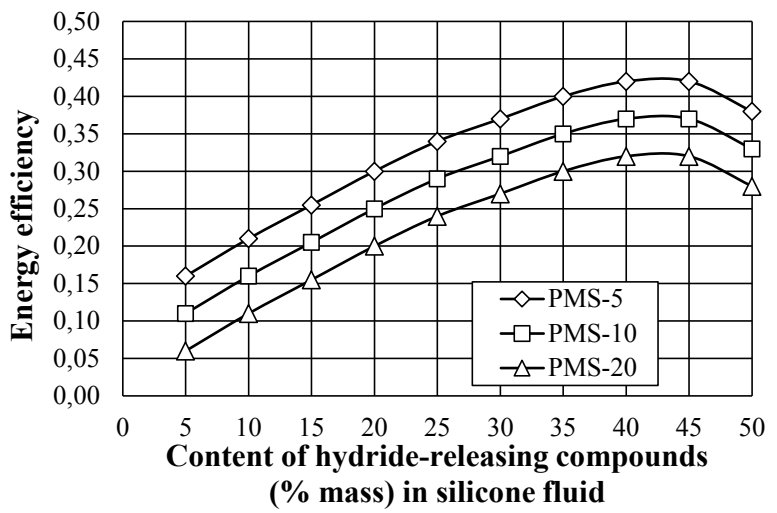

\section{Figure 11. Influence of the content of hydride-releasing compounds} in silicone fluid on the efficiency of the device

Analysis of these data allows to state the following: an increase in the content of hydride-releasing material in the suspension increases the thermal efficiency of the experimental device for the extraction of hydrogen from the gas mixture and reduces the energy consumption for the operation of this device. This fact is explained by the fact that with an increase in the content of hydride-releasing compounds, the energy costs for heating the ballast silicone fluid are reduced, as well as the cost of its transportation.

However, the ratio of hydride-releasing compound/silicone fluid should not exceed 0.45 (by mass) because when this ratio is increased above 0.45 , the energy costs for transporting the suspension through heat and mass transfer devices, pipelines, and the like, connected in series are significantly increased.

The maximum energy efficiency of $38 . . .42 \%$ can be achieved if the above ratio is 0.36 and PMS-5 silicone fluid is used as a carrier. 
The next factor that significantly affects thermal efficiency is the viscosity of the silicone fluid. An increase in viscosity leads to a decrease in thermal efficiency, which significantly increases the hydrodynamic resistance and energy consumption for pumping the suspension through the apparatus and pipeline of the experimental device. This resistance is very significant due to the fact that the number of such devices connected in series is quite large. Thus, if the viscosity of the silicone fluid changes from $5 \mathrm{cSt}$ to $20 \mathrm{cSt}$, the energy efficiency of the experimental device decreases from 0.16 to 0.06 and from 0.36 to 0.28 in accordance with the content of hydride-releasing compounds in the silicone fluid of the suspension.

The pressure of the synthesis gas in the sorber also has a significant effect on the thermal efficiency of the experimental device. This effect depends on the pressure of the synthesis gas and the viscosity of the silicone fluid used as a carrier, shown in Figure 12. Calculations and tests were performed under conditions of using a suspension with a $40 \%$ content of hydride-releasing material.

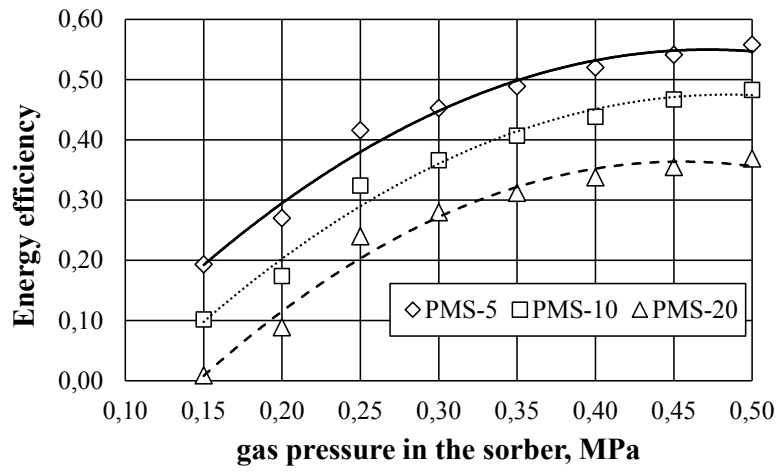

\section{Figure 12. The effect of the pressure of the gas mixture in the sorbent on the device efficiency}

An analysis of these data allows to state the following: the energy efficiency of the experimental device increases with increasing pressure of the gas mixture in the device sorber. These dependencies are almost linear. Increasing viscosity negatively affects energy efficiency. So, for example, if the pressure in the installation sorbent is $0.15 \mathrm{MPa}$, and the viscosity of the suspension is $20 \mathrm{cSt}$, the energy efficiency is only $0.009(0.9 \%)$; if the 
pressure of the gas mixture in the sorber is $0.5 \mathrm{MPa}$ and the viscosity of the suspension is $5 \mathrm{cSt}$, the energy efficiency reaches $0.558(55.8 \%)$.

Unfortunately, an increase in the pressure of the gas mixture in the sorbent is partly due to the negative effect on the overall efficiency of the experimental device. The fact is that increasing the pressure of the gas mixture in the sorbent leads to an increase in the contamination of the silicone fluid with harmful substances present in the gas mixture (carbon monoxide, hydrocarbon gases, etc.). These harmful gases dissolve in the silicone fluid, followed by release in the stripper and pollute the hydrogen, stripped from the hydride. The dependences of hydrogen purity at the outlet of the stripper of the experimental device are shown in Figure 13.

An analysis of these data shows that if it is necessary to obtain highpurity hydrogen, then the pressure of the gas mixture in the sorbing device should be in the range $0.15 \ldots 0.25 \mathrm{MPa}$, however, the energy efficiency of the installation is less than 0.33 and depends on the viscosity of the silicone fluid, as can be seen in Fig. 13. The pressure of the gas mixture in the sorber can be maintained in the range of $0.25 \ldots 0.5 \mathrm{MPa}$, if the purity of the hydrogen produced by the experimental device is not critical. In this case, the energy efficiency of the device reaches 0.56 .

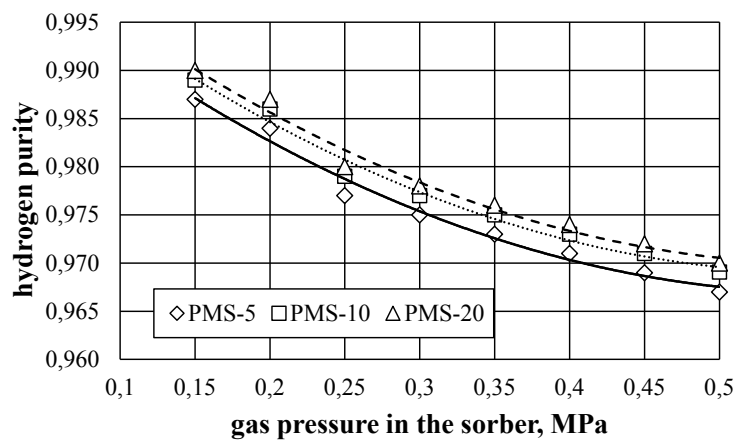

Figure 13. Effect of the pressure of the gas mixture in the sorbent on the hydrogen purity of the device

In any case, the choice of pressure in the device sorbent is a compromise solution and is one of the main tasks in the rational design of equipment for the extraction of hydrogen from gas mixtures. 


\section{Evaluation of the effectiveness of metal hydride thermal sorption device compressing hydrogen to high pressures}

The metal hydride thermal sorption compressor of the device operates on a discrete principle of operation. The energy efficiency of the device depends on numerous factors, such as the duration of the cycle, the temperature level of energy carriers and their distribution over time. These parameters determine the energy consumption for the process and the overall energy efficiency of the experimental device as a whole. The influence of the most important parameters is shown in Figure 14 a.

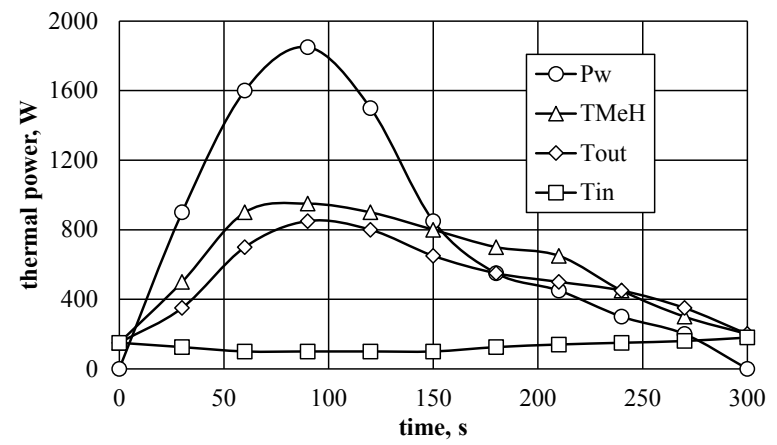

a

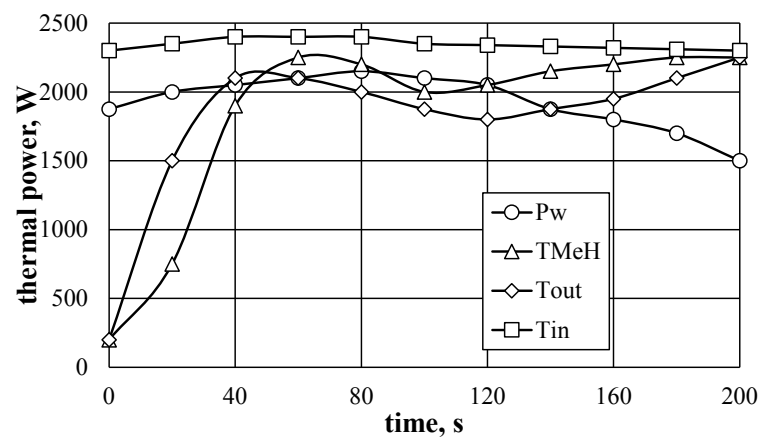

b

Figure 14. Thermal efficiency of a metal hydride experimental device for hydrogen compression 
The initial conditions that were established during these studies are as follows: hydride-releasing material $\mathrm{MmNi}_{4.5} \mathrm{Al}_{0.5}$ in an amount of $4.5 \mathrm{~kg}$; the temperature of the coolant (cooling water) is $298 \mathrm{~K}$, which did not change throughout the experiment.

An analysis of the results of the experiment shows that the thermal power that is removed from the sorber during the working half-cycle is maximum at the 90th second and reaches $1890 \mathrm{~W}$. The maximum temperature of hydride-releasing compounds reaches $58^{\circ} \mathrm{C}$ due to the fact that the kinetics of sorption (the amount of hydrogen absorbed over time) and the total amount of heat of reaction are the largest at present. The temperature of the coolant (cold coolant) is $53^{\circ} \mathrm{C}$. After this time, the hydride-releasing compound absorbed about $65 \%$ of its maximum capacity and the kinetics of sorption is significantly reduced. The amount of heat, the temperature of the hydride-releasing compound and the cooling water are reduced accordingly.

At the 300th second, the process of sorption (extraction) of hydrogen is almost complete. The hydride-releasing compound is completely saturated with hydrogen and is ready for the next half-cycle of hydrogen desorption (compression).

The effectiveness of this half-cycle depends on the same factors as those indicated above: the duration of the cycle is the temperature level of energy carriers and their distribution over time. These parameters also determine the energy consumption and efficiency of the experimental device as a whole. The influence of these most important parameters is presented in Figure $14 \mathrm{~b}$. The initial conditions of the experiment are as follows: the temperature of the hot heat carrier (water) at the inlet to the stripper (compressor) is $81.6^{\circ} \mathrm{C}$ and practically does not change during the research.

An analysis of these results shows that the thermal power is supplied to the hydride-releasing compounds of the stripper during the entire halfcycle, approximately constant, but its maximum values are in the range between $40 \ldots 100$ seconds and reach $2250 \mathrm{~W}$.

The maximum hydride temperature reaches $80.5^{\circ} \mathrm{C}$, due to the fact that the kinetics (the amount of hydrogen stripped over time) and the total amount of absorbed heat of the reaction are the largest at this time. The temperature of the hot fluid at the outlet of the stripper (compressor) is $75^{\circ} \mathrm{C}$.

After such heating of hydride-releasing compound is sorbed up to $85 \%$ hydrogen from its maximum capacity and the kinetics of desorption 
are significantly reduced. The amount of heat, the temperature of the hydride-releasing compound and the hot coolant at the outlet of the stripper (compressor) increase accordingly. At the 200th second, the process of hydrogen desorption (compression) is almost complete. The hydride-releasing compound is completely free of hydrogen and is ready for the start of the next half-cycle - sorption (extraction) of hydrogen from the gas mixture.

The overall energy efficiency of the experimental device consists of the per-formance indicators of individual elements, such as a sorber, stripper, heat exchangers, liquid energy pumps, coolants, cooling agents, and other devices that are necessary for the device operation. Thus, the energy efficiency of the experimental device can be found as a complex of multiplication of all elements and auxiliary equipment that ensures the operation of the experimental device:

$\eta_{\text {ex }}=\eta_{\text {sorber }} \times \eta_{\text {stripper }} \times \eta_{\text {heater } 1} \times \eta_{\text {heater } 2} \times \ldots \times \eta_{\text {heater n }} \times \eta_{\text {cooler } 1} \times{ }_{\text {coooler } 2} \times \ldots \times \eta_{\text {heater }}$

It is very difficult to calculate theoretically the effectiveness of the experi-mental device because it is a problem with many unknown quantities. The easiest and most accurate way to determine this efficiency is experimentally. The real energy efficiency of the experimental device for extracting hydrogen from a gas mixture and compressing this hydrogen to high pressures is presented in Table 2 .

Table 2

Energy efficiency of a hydrogen extraction experimental device

\begin{tabular}{|l|c|c|}
\hline \multicolumn{1}{|c|}{ Parameter } & Dimension & Value \\
\hline $\begin{array}{l}\text { Energy consumption for removing hydrogen in a } \\
\text { sorber }\end{array}$ & $(\mathrm{KW} \times \mathrm{h}) / \mathrm{kg} \mathrm{H}_{2}$ & 1,22 \\
\hline $\begin{array}{l}\text { Energy consumption for hydrogen evolution in the } \\
\text { stripper }\end{array}$ & $(\mathrm{KW} \times \mathrm{h}) / \mathrm{kg} \mathrm{H}_{2}$ & 14,93 \\
\hline $\begin{array}{l}\text { Energy consumption for sorption of hydrogen from } \\
\text { a stripper of a hydrogen recovery device; a sorber } \\
\text { of a hydrogen compression device }\end{array}$ & $(\mathrm{KW} \times \mathrm{h}) / \mathrm{kg} \mathrm{H}_{2}$ & 1,87 \\
\hline $\begin{array}{l}\text { Energy consumption for hydrogen removal (com- } \\
\text { pression up to 15 MPa) from hydride in the stripper } \\
\text { of the compressor device }\end{array}$ & $(\mathrm{KW} \times \mathrm{h}) / \mathrm{kg} \mathrm{H}_{2}$ & 21,08 \\
\hline $\begin{array}{l}\text { The total energy consumption of a device for } \\
\text { extracting hydrogen from a gas mixture and } \\
\text { compressing this hydrogen to 15 MPa }\end{array}$ & $(\mathrm{KW} \times \mathrm{h}) / \mathrm{kg} \mathrm{H}_{2}$ & 39,10 \\
\hline
\end{tabular}


The initial conditions of the experiment are as follows:

1. The liquid carrier is polymethylsiloxane PMS-10 with a viscosity of $10 \mathrm{cSt}$.

2. The content of hydride-releasing material in the suspension is $30 \%$ (mass).

3. The temperature of the hot fluid at the inlet (water) is $85^{\circ} \mathrm{C}$.

4. The temperature of the cooling water is $22^{\circ} \mathrm{C}$.

5 . The productivity of the device for compressed hydrogen (15.2 $\mathrm{MPa})$ is $63 \mathrm{~g} / \mathrm{h}$.

Such a sense of energy efficiency can be significantly improved in the design of an industrial device. This is entirely possible because fullsized industrial equipment will have higher efficiency and performance. The experimental device consists of samples of equipment of reduced size, which have significantly worse efficiency compared to industrial designs. In addition, industrial equipment and the device as a whole will have relatively small losses of energy in the environment, which also increases its efficiency.

\section{Conclusions}

1. The experimental data allow to conclude that the developed devices can be used to study the processes of hydrogen extraction from a gas mixture formed during the decomposition of hydrogen sulfide using metal hydride technologies.

2. Experimental studies have confirmed the feasibility and effectiveness of metal hydride technologies, and also with sufficient accuracy allowed to obtain the nature of changes in the main parameters of the process of hydrogen extraction from a gas mixture. The kinetic characteristics of the experimental device were studied and the performance of the process of extracting hydrogen from the gas mixture was established. The lowest productivity of hydrogen absorption is at a pressure of a gas mixture of $0.2 \mathrm{MPa}$ and a temperature of $313 \mathrm{~K}-0.9 \mathrm{~g} / \mathrm{min}$. The maximum productivity of hydrogen absorption from the gas mixture reaches $2.3 \mathrm{~g} / \mathrm{min}$ at a suspension temperature of $298 \mathrm{~K}$ in the stripper and a pressure of $0.3 \mathrm{MPa}$.

3. The dynamics of the relative mass of hydrogen freed from high pressure battery/compressor depending on the heating temperature. Raising the heating temperature from $75^{\circ} \mathrm{C}$ to $90^{\circ} \mathrm{C}$ allows the release of $95 \%$ hydrogen at high 
pressure. A suspension of hydride-releasing material absorbs hydrogen very quickly if the temperature of the cooling water is minimal.

4. The increase in the content of hydride-releasing material in the suspension increases the thermal efficiency of the experimental device for the extraction of hydrogen from the gas mixture and reduces the energy consumption for the operation of this device. With an increase in the content of hydride-releasing compounds, the energy costs for heating the ballast silicone fluid decrease, as well as the cost of its transportation.

\section{References:}

1. Ministry of Ecology and Natural Resources of Ukraine (2002). Stan dovkillja Chornogho morja [The state of the environment of the Black Sea]. Odesa: Ministry of Ecology and Natural Resources of Ukraine. (in Ukrainian)

2. Dimitrov D., Dimitrov P. (2010). Chernoe more - netraditsionnyy energeticheskiy i syr'evoy tsentr Evropy [The Black Sea is an unconventional energy and raw material center of Europe]. Geology and mineral resources of the Oceans, vol. 2, pp. 27-34.

3. Neklyudov I.M., Borts B.V., Polevich O.V., Tkachenko V.I., Shilyaev B.A. (2006). Al'ternativnaya serovodorodnaya energetika Chernogo morya, sostoyanie, problemy i perspektivy. Chast' I [Alternative hydrogen sulphide energy of the Black Sea, state, problems and prospects. Part I]. Hydrogen Energy and Transport, vol. 12(44), pp. 23-30.

4. Tarasov B.P., Lototskiy M.V., Yartys' V.Ya. (2006). Problema khraneniya vodoroda i perspektivy ispol'zovaniya gidridov dlya akkumulirovaniya vodoroda [The problem of hydrogen storage and the prospects for using hydrides for hydrogen storage]. Russian Chemical Journal, vol. L, no. 6, pp. 34-48.

5. Kolachev B.A., Shalin R.E., Il'in A.A. (1995). Splavy-nakopiteli vodoroda: Spravochnik [Hydrogen Storage Alloys: A Guide]. Moscow: Metalurgiya. (in Russian)

6. Broom D. (2011). Hydrogen Storage Materials / The Characterisation of Their Storage Properties. Springer. 